Check for updates

Cite this: RSC Adv., 2018, 8, 8836

Received 6th December 2017 Accepted 14th February 2018

DOI: 10.1039/c7ra13092a

rsc.li/rsc-advances

\section{Mechanism investigation on the reactions of $\mathrm{ClF}_{3} \mathrm{O}$ and $n$-decane by combining density functional theory and spontaneous emission spectroscopy $\dagger$}

\author{
Xinghua Liu, (D) ${ }^{a}$ Hua Yan, ${ }^{a}$ Daxi Wang, ${ }^{a}$ Yue Ma, ${ }^{a}$ Shuyuan Li, ${ }^{\text {ta }}$ Yongfeng Luo ${ }^{a}$ \\ and Shengli $\mathrm{Xu}^{\mathrm{b}}$
}

The mechanism of the reactions of $\mathrm{ClF}_{3} \mathrm{O}$ and $n$-decane had two stages. The first stage was the initial reaction between $\mathrm{ClF}_{3} \mathrm{O}$ and $n$-decane. The initial reactions were investigated using a density functional theory (DFT) method. The results showed that the critical part of the mechanism of the initial reaction was the roaming of the $\mathrm{HF}$ intermediate. $\mathrm{A} \mathrm{H}$ atom on $n$-decane was abstracted by a $\mathrm{F}$ atom on $\mathrm{ClF}_{3} \mathrm{O}$ to produce HF. The formed HF roamed around and then broke to give CIFO, fluorinated decane and a new $\mathrm{HF}$ molecule. The initial reactions were considered to be barrier-less reactions and extremely exothermic. The average released energy of the initial reactions was $412.9 \mathrm{~kJ} \mathrm{~mol}^{-1}$, which was great enough to cause thermal decomposition of $n$-decane. The second stage included the reaction between $\mathrm{CIFO}$ and $n$-decane and the thermal decomposition of $n$-decane. The secondary reactions involving $\mathrm{CIFO}$ were also studied using a DFT method. $\mathrm{CIFO}$ was less reactive than $\mathrm{ClF}_{3} \mathrm{O}$. The average energy barrier of the reactions of CIFO and $n$-decane was $116.3 \mathrm{~kJ} \mathrm{~mol}^{-1}$ and the average released energy was $266.5 \mathrm{~kJ} \mathrm{~mol}^{-1}$. Thermal decomposition of $n$-decane was evidenced by the emission spectra of the characteristic radical intermediates $\mathrm{CH}$ and $\mathrm{C}_{2}$, which were observed using an intensified chargecoupled device (ICCD) system. The main gaseous products of the thermal decomposition of $n$-decane, as identified using gas chromatography, were hydrogen, ethylene and acetylene. The experimental results showed that the thermal decomposition of $n$-decane was an important secondary reaction following the initial reactions.

\section{Introduction}

Halogen fluorides and their oxides are widely used as oxidizers, fluorinating agents, accelerators and initiators in the military and the semiconductor industry due to their unique chemical properties. $^{1-4}$ Fundamental investigations of halogen fluorides and their oxidized derivatives, such as the study of the synthetic methods, crystal structures, spectra, thermodynamic properties and reactivity, have been conducted systematically since the 1960s. ${ }^{5-12}$ Halogen fluorides and their related oxides have extremely active chemical reactivity, and can react with fossil fuels violently. However, only a few studies focusing on the reaction mechanism have been reported. Brower et al. reported the reaction mechanism of $\mathrm{ClF}_{3}$ reacting with hydrocarbons. They proposed that this type of reaction followed an ionic mechanism, shown as reaction (1) in Scheme $1 .^{1,13}$ A front-sided transition state was formed, and two fluorine atoms were

${ }^{a}$ College of Science, China University of Petroleum-Beijing, State Key Laboratory of Heavy Oil Processing, Beijing 102249, China. E-mail: syli@cup.edu.cn ${ }^{b}$ School of Aerospace Engineering, Tsinghua University, Beijing 100084, China

$\dagger$ Electronic supplementary information (ESI) available. See DOI: 10.1039/c7ra13092a consumed to give a fluorinated hydrocarbon and hydrogen fluoride. Niu et al. ${ }^{\mathbf{1 4}}$ calculated the reaction pathways for $\mathrm{ClF}_{3} \mathrm{O}$ reacting with propane using DFT theory. They obtained nine different pathways that satisfied reaction eqn (2) in Scheme 1. ${ }^{\circ} \mathrm{C}_{3} \mathrm{H}_{7}$ and ${ }^{\circ} \mathrm{ClF}_{2} \mathrm{O}$ radicals were formed, showing that a free radical mechanism was involved. The average calculated energy barrier was about $8 \mathrm{~kJ} \mathrm{~mol}^{-1}$. This indicates that this reaction occurred readily at room temperature. Du et al. ${ }^{15}$ showed that the reactions between halogen fluorides and hydrocarbons were exothermic, and the released energy was sufficient to lead to the homolysis of $\mathrm{C}-\mathrm{C}$ bonds on hydrocarbons. Baddiel et al. ${ }^{\mathbf{1 6}}$ published a study about the mechanism for the reaction between $\mathrm{ClF}_{3}$ and methane. They concluded that a free radical

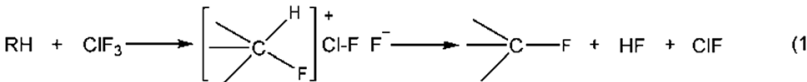

$$
\begin{aligned}
& \mathrm{ClF}_{3} \mathrm{O}+\mathrm{C}_{3} \mathrm{H}_{3} \longrightarrow \mathrm{C}_{3} \mathrm{H}_{7}+\mathrm{HF}+\cdot \mathrm{ClF}_{2} \mathrm{O} \\
& \cdot \mathrm{CH}+\mathrm{CH}_{4} \longrightarrow \mathrm{C}_{2} \mathrm{H}_{2}+\mathrm{H}_{2}+\cdot \mathrm{H} \\
& \cdot \mathrm{CH}+\mathrm{CH}_{4} \longrightarrow \mathrm{C}_{2} \mathrm{H}_{4}+\cdot \mathrm{H}
\end{aligned}
$$

Scheme 1 Previously reported reactions of halogen fluorides or their related oxides with hydrocarbons. 
chain mechanism was in operation for this reaction. $\mathrm{A} \mathrm{CH}$ radical was involved as shown in Scheme 1 (reactions (3) and (4)). They also claimed that the mechanism was shared by other hydrocarbon pyrolytic processes. However, they didn't demonstrate how $\mathrm{ClF}_{3}$ reacted with methane. To the best of our knowledge, the reaction mechanism between $\mathrm{ClF}_{3} \mathrm{O}$ and fossil fuels isn't fully understood. In the present study, $n$-decane was chosen as a representative fossil fuel. The reaction of $n$-decane and $\mathrm{ClF}_{3} \mathrm{O}$ was studied using theoretical and experimental methods. DFT computation was employed to calculate the possible initiation pathways. An ICCD system was used to verify whether a radical mechanism was involved or not by detecting the appearance of $\mathrm{CH}$ and $\mathrm{C}_{2}$ radical intermediates. The aim of the present study is to obtain a better understanding of the reactions mentioned above.

\section{Computational and experimental methods}

\subsection{Calculation methods}

All of the calculated reaction pathways are shown in Scheme 2. $\mathrm{ClF}_{3} \mathrm{O}$ reacts with $n$-decane to give $\mathrm{HF}, \mathrm{ClFO}$ and a corresponding fluorinated product. ClFO is an active intermediate and can abstract a hydrogen atom from $n$-decane to form $\mathrm{HF}, \mathrm{HClO}$ and a corresponding alkene. For the ground state (the singlet state), all of the geometries of the reactants, transition states, intermediates and products were optimized using the B3PW91 method with a $6-31++\mathrm{G}(\mathrm{d}, \mathrm{p})$ basis set, which has been proven to be accurate enough for the current system. ${ }^{\mathbf{1 4 , 1 7}}$ Frequency calculations were performed to verify that there was only one imaginary frequency for transition states and no imaginary frequency for the rest of the stationary states. Intrinsic reaction coordinate analysis (IRC) was employed to confirm the transition states connecting to the proper reactants and products. ${ }^{18,19}$ The excited state (the triplet state) computations were carried out at the UB3PW91/6-31++G(d,p) level of theory in order to examine the possibility of a radical mechanism. Enthalpies were calculated at the B3PW91/6-31++G(d,p) level of theory at 298.15 $\mathrm{K}$ and 0.2 MPa. The energy barrier was defined as the

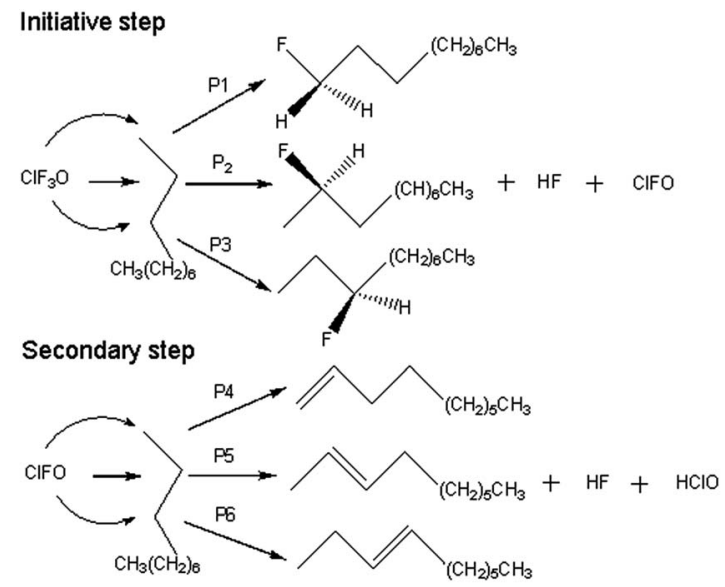

Scheme 2 Reaction pathways for DFT computations. enthalpy difference between the transition state and the reactant. Similarly, the released energy was calculated from the enthalpy difference between the product and the reactant. All of the calculations were done using the Gaussian 03 program. ${ }^{20}$

\subsection{Emission spectra determination}

The experiments were performed in a $4 \mathrm{~L}$ stainless steel cylinder reactor. The diagram of the experimental setup is shown in Fig. 1. $n$-Decane ( 1.0 g, 99\%, purchased from Tianjin chemical reagent factory) was placed in a crucible at the bottom of the reactor. $\mathrm{ClF}_{3} \mathrm{O}(\sim 0.1 \mathrm{~g}, 99 \%$, purchased from Tianjin chemical reagent factory) was placed in a container at the top of the reactor. $\mathrm{ClF}_{3} \mathrm{O}$ could flow downwards onto the crucible through a tube and react with $n$-decane. The reaction would lead to chemiluminescent emissions, which were exported by two optics probes located $10 \mathrm{~mm}$ above the crucible on the side of the reactor wall. One fiber was connected to a time-gated 2561024 element ICCD camera (Princeton Instruments) with a measuring range from 200 to $900 \mathrm{~nm}$. The ICCD camera was coupled with a spectrometer (Acton spectra-Pro-275), which was calibrated using a mercury lamp. $\mathrm{CH}$ radical chemiluminescence was defined as the starting point of the thermal decomposition and was the trigger signal of the ICCD camera. ${ }^{21,22}$ Another fiber was connected with a $431 \mathrm{~nm}$ optical filter, and then the optical signal was transformed into an electric current $(\sim-50 \mathrm{mV})$ by a photomultiplier tube (PMT, Thorlabs), and the electric current was further amplified 100 times $(\sim 5 \mathrm{~V})$ by an inverting amplifier. Then a delay generator (DG645, Stanford research) and the ICCD were triggered sequentially. Hence, the emission spectra were recorded synchronously.

\subsection{Gaseous product determination}

The gaseous products were passed through caustic soda solution to remove HF and other acidic gases and then analyzed using an Agilent 6890 GC System gas chromatograph, with a configuration of an HP-AL/S capillary column $(25 \mathrm{~m} \times$ $0.32 \mathrm{~mm}$ i.d. $\times 0.5 \mu \mathrm{m})$, a DM-PLOT 5A molecular sieve column (3 $\mathrm{m} \times 4 \mathrm{~mm}$ i.d. $\times 180-250 \mu \mathrm{m})$ and a ProPark column $(3 \mathrm{~m} \times$ $4 \mathrm{~mm}$ i.d. $\times 150-180 \mu \mathrm{m})$. The flow of $\mathrm{N}_{2}, \mathrm{H}_{2}$ and air was $4 \mathrm{~mL} \mathrm{~min}^{-1}, 40 \mathrm{~mL} \mathrm{~min}^{-1}$ and $300 \mathrm{~mL} \mathrm{~min}^{-1}$, respectively. The

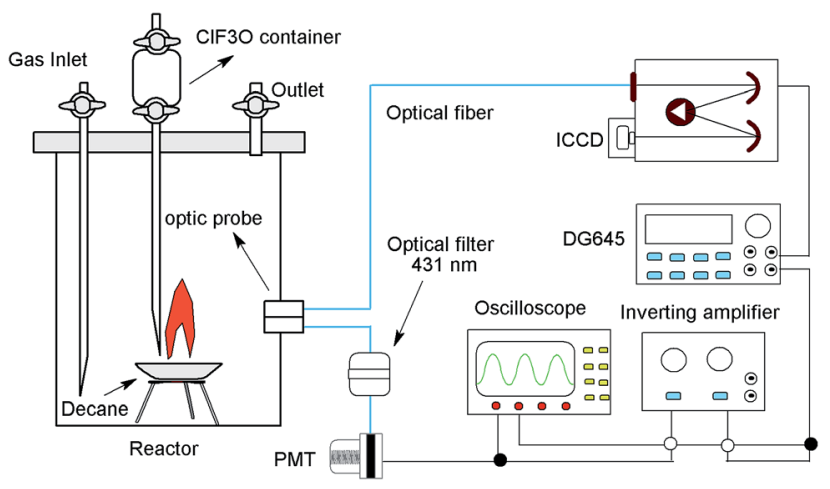

Fig. 1 The diagram of the ICCD testing system. 
temperature of the inlet, FID detector and TCD detector was $250{ }^{\circ} \mathrm{C}$. The programmed column temperature was elevated from $50{ }^{\circ} \mathrm{C}$ to $100{ }^{\circ} \mathrm{C}$ at a rate of $5{ }^{\circ} \mathrm{C} \mathrm{min}{ }^{-1}$, and then heated up to $180{ }^{\circ} \mathrm{C}$ at a heating rate of $10^{\circ} \mathrm{C} \mathrm{min}{ }^{-1}$. The holding time was $3 \mathrm{~min}$. Gaseous products including $\mathrm{C}_{1}-\mathrm{C}_{5}$ light hydrocarbons and inorganic gases were quantified using an external standard method. As reported previously, ${ }^{\mathbf{2 3 , 2 4}}$ the relative error of quantities for gaseous products measured using this device was less than $0.5 \%$.

\section{Results and discussion}

\subsection{Geometries}

The initial geometric parameters of $\mathrm{ClF}_{3} \mathrm{O}$ were adopted from the electron diffraction data reported by Oberhammer, ${ }^{12}$ and then the geometry was fully optimized at the B3PW91/631++G(d,p) level. $\mathrm{ClF}_{3} \mathrm{O}$ has distorted trigonal bipyramidal geometry. The linear configuration of $n$-decane was employed and optimized at the same level of theory. The initial states (ISs), transition states (TSs) and final states (FSs) of different pathways can be found in the ESI. $\dagger$ Only the geometries of P1 are shown in Fig. 2. For the initiation stage, the related geometries of P1, P2 and P3 are similar, indicating that the position of the hydrogen atom is not an important factor for the reaction mechanism. Taking pathway P1 as an example, P1IS is the initial state of pathway $\mathrm{P} 1$, in which an $\mathrm{F}$ atom points towards an $\mathrm{H}$ atom on the methyl group at the end of $n$-decane. For the transition state P1TS, the corresponding $\mathrm{Cl}-\mathrm{F}$ bond and $\mathrm{C}-\mathrm{H}$ bond are elongated while the distance between $\mathrm{H}$ and $\mathrm{F}$ decreases. Meanwhile, the bond length of the other two Cl-F bonds also increases. In the final state P1FS, $\mathrm{H}$ is substituted by $\mathrm{F}$ to give 1-fluorodecane. Another $\mathrm{F}$ atom is consumed by $\mathrm{H}$ to yield HF. The third product of pathway P1 is ClFO. The geometry of P1TS is similar to that of P1IS, showing that this reaction is an exothermic process according to Hammond's postulate. ${ }^{25}$ Not surprisingly, P1TS is totally geometrically different from P1FS.

In order to interpret how P1IS transforms into P1FS, the related geometries along the IRC path of P1 are given in Fig. 3 and the related bond length and bond angle changes are plotted

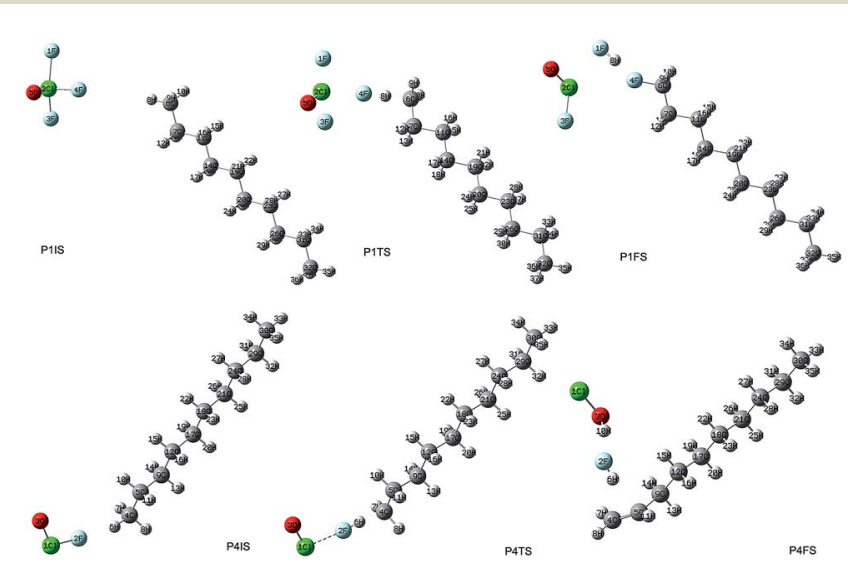

Fig. 2 The geometries of IS, TS, and FS for pathway 1 and pathway 4.

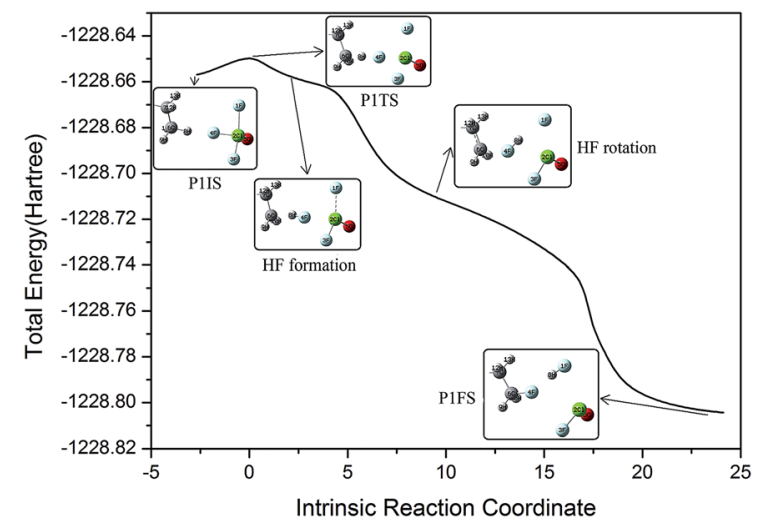

Fig. 3 Different geometries along the intrinsic reaction coordinate of P1.

in Fig. 4. The transition state P1TS experiences two different steps, "HF formation" and "HF rotation", before transforming into P1FS as shown in Fig. 3. In the "HF formation" step, HF is formed naturally from P1TS, but it is not the end of this reaction. Then the formed HF rotates around by itself. As a result, in the "HF rotation" step, F4 is approaching $\mathrm{C} 6$ and $\mathrm{H} 8$ is pointing to F1. In the geometry of P1FS, a new HF is formed while the original HF decomposes. As shown in Fig. 4, the length of F4-H8 decreases from $1.8 \AA$ to $0.9 \AA$, which means that the H8-F4 bond is formed. Then the bond length keeps constant over the coordinate interval from coordinate 2 to coordinate 15 , meanwhile the angle C6-F4-H8 increases rapidly and reaches $131^{\circ}$ at coordinate 9 . The increment of the angle C6-F4-H8 indicates the rotation of the HF molecule. The H8-F4 bond breaks gradually starting from coordinate 15, while the H8-F1 bond is formed at the same time. The distance of F4-C6 drops slowly along the reaction coordinate before the C6-F4 bond is formed at coordinate 20 . The increasing trend of the bond length of $\mathrm{C} 6-\mathrm{H} 8$ shows that $\mathrm{H} 8$ is abstracted from the $n$-decane molecule by $\mathrm{ClF}_{3} \mathrm{O}$. The interesting aspect of pathway $\mathrm{P} 1$ is the roaming of the $\mathrm{H} 8 \mathrm{~F} 4$ intermediate. It is the key to understanding the front-sided fluorinated reaction. Two $\mathrm{F}$ atoms are

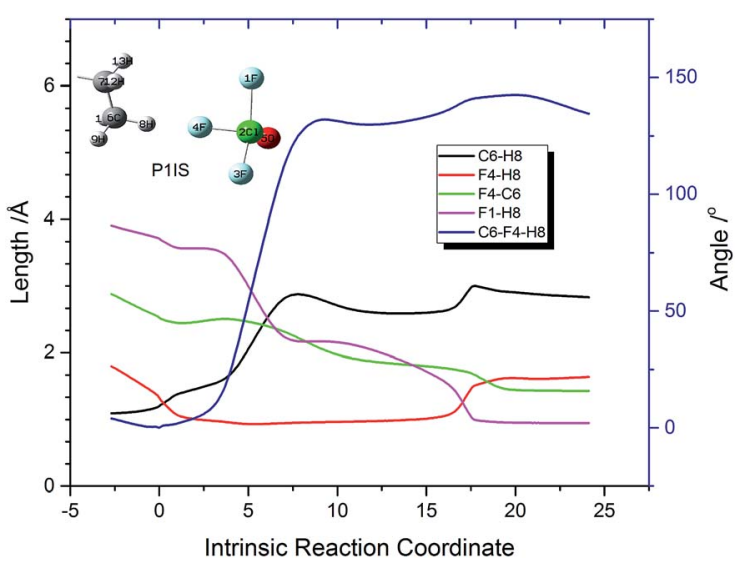

Fig. 4 Related geometry changes along the intrinsic reaction coordinate of $\mathrm{P} 1$ 
consumed in this process, which is consistent with the mechanism proposed by Brower. ${ }^{13}$

The reactions of ClFO and $n$-decane were also calculated with the aim of investigating the reactivity of ClFO. All of the corresponding geometries P4, P5 and P6 can be seen in S1.† Only the geometries of $\mathrm{P} 4$ are shown in Fig. 2. The reactions occurring via pathways P4, P5 and P6 are similar. Taking P4 as an example, the $\mathrm{F}$ atom continuously gets closer to the $\mathrm{H}$ atom on the methyl group while the $\mathrm{C}-\mathrm{H}$ bond starts to break. Then the $\mathrm{O}$ atom keeps approaching the $\mathrm{H}$ atom on the adjacent methylene group. Therefore, two $\mathrm{H}$ atoms are abstracted by ClFO spontaneously to give $\mathrm{HF}$ and $\mathrm{HClO}$, and a $\mathrm{C}=\mathrm{C}$ double bond is generated by the loss of two hydrogen atoms.

The $\mathrm{F}$ atom on $\mathrm{ClF}_{3} \mathrm{O}$ attacks the $\mathrm{H}$ atom on $n$-decane to initialize the reactions, and the formed $\mathrm{HF}$ intermediate roams and leads to substitution products for the initiation step. The secondary step belongs to an abstraction reaction. HF is the common product of the initiation reaction and the secondary reaction involving ClFO. The calculation results also state that the positions of the $\mathrm{H}$ atoms have no effect on the reaction mechanism.

\subsection{Energetics}

The energy profiles of the initiation step and the secondary step involving ClFO are summarized in Fig. 5. $\mathrm{ClF}_{3} \mathrm{O}$ is a highly reactive compound. The energy barrier of the initiation step is lower than $5 \mathrm{~kJ} \mathrm{~mol}^{-1}$. This shows that the initiation step can be considered as a barrier-less process. The average released energy for the initiation step is $412.9 \mathrm{~kJ} \mathrm{~mol}^{-1}$, which is greater than the bond dissociation energy of the $\mathrm{C}-\mathrm{C}$ bond and $\mathrm{C}-\mathrm{H}$ bond of $n$-decane. ${ }^{26}$ The energy differences among P1, P2 and P3 are very small. The general trend is that the closer the location of hydrogen to the chain terminal of $n$-decane, the greater the energy barrier is and the less the released energy is. This is because the $\mathrm{C}-\mathrm{H}$ bond on the methyl group has more bond dissociation energy than other $\mathrm{C}-\mathrm{H}$ bonds on $n$-decane.

The average value of the energy barrier for the secondary step involving ClFO is $116.3 \mathrm{~kJ} \mathrm{~mol}^{-1}$, which is much higher than that of the initiation step. The amount of released energy, with

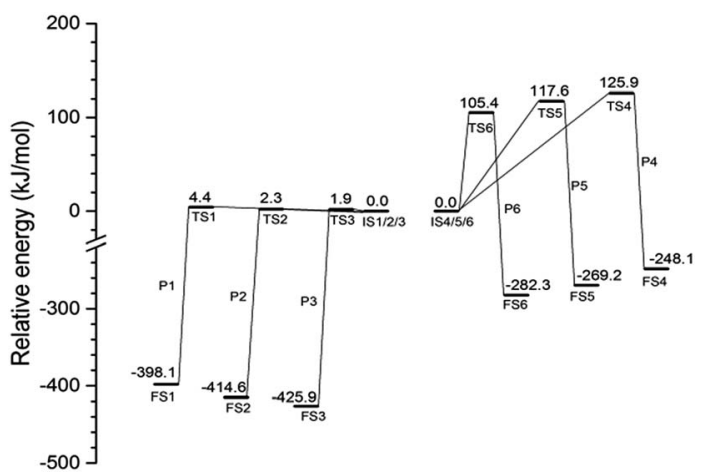

Fig. 5 Energy profile of reaction pathways calculated at the B3PW91/ $6-31++G(d, p)$ level with ZPE correlation. an average value of $266.5 \mathrm{~kJ} \mathrm{~mol}^{-1}$, is also smaller than the energy of the initiation step. Therefore, the reactivity of ClFO is much weaker than that of $\mathrm{ClF}_{3} \mathrm{O}$. In addition, theoretically, the energy released during the initiation process can lead to thermal decomposition of $n$-decane. The thermal decomposition reactions compete with the secondary reactions involving ClFO. The possibility of the thermal decomposition of $n$-decane was further verified by the experimental results of spontaneous emission spectroscopy.

\subsection{The excited state computation}

Excited state computations were carried out to verify the radical mechanism. 38 points along the IRC of P1 in the ground state were selected. The excited state potential energy surfaces were calculated on the geometries of the ground state. The potential energy surfaces of the ground state and the excited state are shown in Fig. 6. It is clearly shown that the potential energy surface of the excited state is above that of the ground state, suggesting a non-radical mechanism.

In addition, a relaxed potential energy surface scan was performed in the triplet state. The distance between the $\mathrm{F}$ atom on $\mathrm{ClF}_{3} \mathrm{O}$ and the $\mathrm{H}$ on the methyl group of $n$-decane was selected as the scan coordinate (the geometry is the same as that of P1IS). The distance decreased from $1.88 \AA$ to $1.08 \AA$ by the step size of $-0.1 \AA$. The potential energy surface of the triplet state was obtained. Then the potential energy surface of the singlet state was calculated on the triplet geometries obtained using the relaxed potential energy surface scan. The potential energy surfaces of the triplet and singlet states were compared and are shown in Fig. 7. The results showed that the potential energy surface of the triplet state was above that of the singlet state. Therefore, the ground state pathway is a possible reaction channel, while the excited state pathway is energetically unfavorable.

\subsection{Emission spectra of $\mathrm{C}_{2}, \mathrm{CH}$ and $\mathrm{OH}$ radicals}

The emission spectra of $n$-decane/ $\mathrm{ClF}_{3} \mathrm{O}$ in $\mathrm{N}_{2} / \mathrm{O}_{2}$ under $0.2 \mathrm{MPa}$ at room temperature were obtained and are plotted in Fig. 8. Under the $\mathrm{N}_{2}$ atmosphere, the primary peak was found at

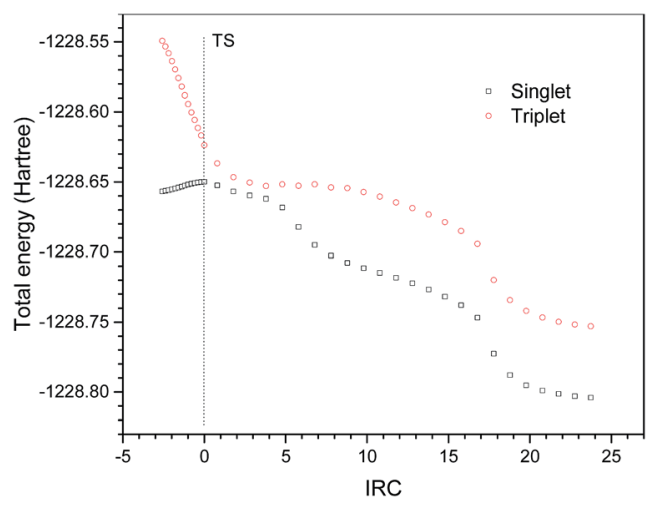

Fig. 6 Singlet and triplet potential energy surfaces of selected points on the singlet geometries along IRC of P1. 


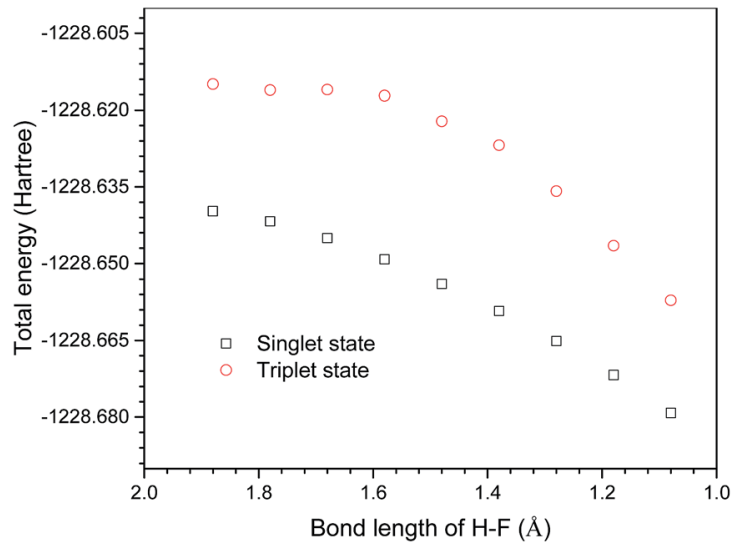

Fig. 7 Singlet and triplet potential energy surfaces on triplet geometries produced by the relaxed potential energy surface scan.

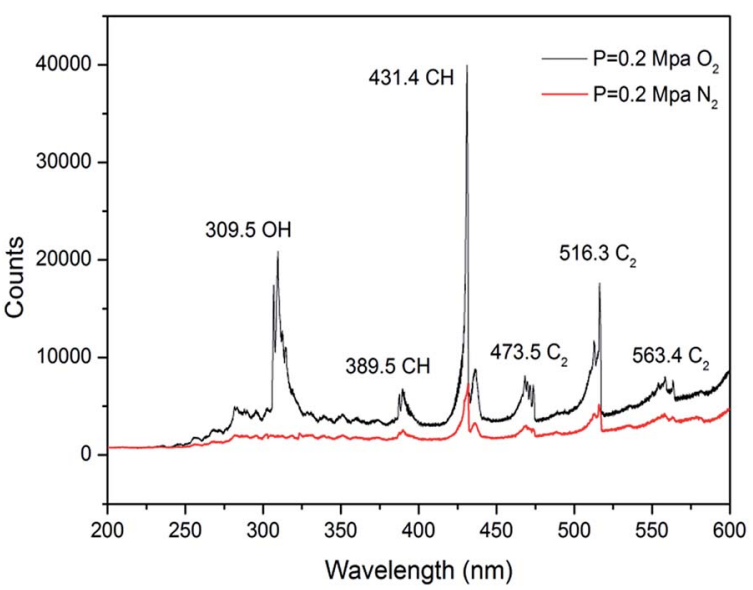

Fig. 8 Emission spectra of $n$-decane/ $\mathrm{ClF}_{3} \mathrm{O}$ in $\mathrm{N}_{2} / \mathrm{O}_{2}$ at room temperature.

$431 \mathrm{~nm}$ corresponding to the $\mathrm{A}^{2} \Delta-\mathrm{X}^{2} \Pi$ electronic transition of the $\mathrm{CH}$ radical. ${ }^{27}$ The peak at $516 \mathrm{~nm}$ produced by the $\mathrm{A}^{3} \Pi_{\mathrm{g}}-$ $\mathrm{X}^{3} \Pi_{\mathrm{u}}$ electronic transition of the $\mathrm{C}_{2}$ radical was also observed. The detection of the $\mathrm{CH}$ and $\mathrm{C}_{2}$ radical intermediates shows clearly that a large amount of energy is released during the process of the reaction between $\mathrm{ClF}_{3} \mathrm{O}$ and $n$-decane. The released energy breaks $\mathrm{C}-\mathrm{C}$ and $\mathrm{C}-\mathrm{H}$ bonds to produce $\mathrm{CH}$ and $\mathrm{C}_{2}$ radicals. The spectrum is consistent with the predictions of the DFT calculations. The initiation step is extremely exothermic. For the $\mathrm{O}_{2}$ atmosphere, the intensity of the spectrum is much stronger than that of the spectrum obtained under the $\mathrm{N}_{2}$ atmosphere. The intensity ratio of $\mathrm{CH}_{\mathrm{N}_{2}}: \mathrm{CH}_{\mathrm{O}_{2}}$ is about $1: 6$. The new peak at $309 \mathrm{~nm}$ corresponds to the $\mathrm{A}^{2} \Sigma^{+}-$ $\mathrm{X}^{2} \Pi_{\mathrm{i}}$ electronic transition of the $\mathrm{OH}$ radical. Small peaks at 389, 473 and $563 \mathrm{~nm}$ are attributed to $\mathrm{CH}, \mathrm{C}_{2}$ and $\mathrm{C}_{2}$ radicals, respectively. $\mathrm{CH}$ and $\mathrm{C}_{2}$ radicals formed by the initiation step of the reactions of $\mathrm{ClF}_{3} \mathrm{O}$ and $n$-decane can react with $\mathrm{O}_{2}$ and then initialize combustion reactions. Consequently, $\mathrm{ClF}_{3} \mathrm{O}$ acts as an initiator in this process.

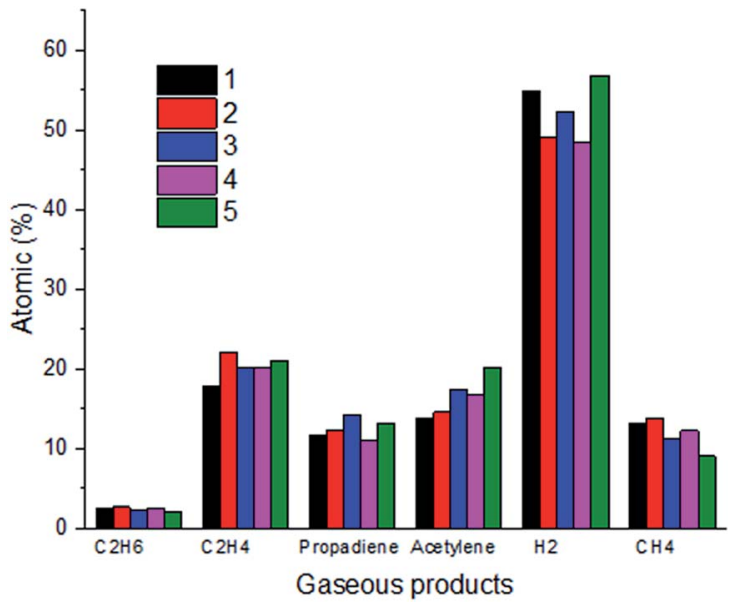

Fig. 9 Gaseous product distribution (the ratio of $\mathrm{ClF}_{3} \mathrm{O}$ to $n$-decane is $1: 10$, and five parallel experiments were conducted).

\subsection{The gaseous product distribution}

In order to further verify the occurrence of thermal decomposition in the process of the reactions of $n$-decane and $\mathrm{ClF}_{3} \mathrm{O}$, the gaseous products were identified using gas chromatography. Besides HF, six gaseous products were found and their quantities are summarized in Fig. 9. It is worth noticing that the content of hydrogen accounts for around $50 \%$, which is 2.5 times greater than that of the second most produced product ethylene. The formation of hydrogen is extremely endothermic and consumes more energy compared to the formation of other species, because $\mathrm{C}-\mathrm{H}$ bonds need to break to form hydrogen molecules. According to the computational results, the first step of the reaction between $\mathrm{ClF}_{3} \mathrm{O}$ and $n$-decane releases $412.9 \mathrm{~kJ} \mathrm{~mol}^{-1}$ on average. The released energy can break $\mathrm{C}-\mathrm{H}$ bonds easily. The amounts of propadiene and acetylene are over $10 \%$, while the amounts of methane and ethane are less than $10 \%$. The product distribution shows clearly that thermal decomposition takes place after the initiation step. Halohydrocarbons were not detected since most halohydrocarbons are liquid.

\section{Conclusions}

Two stages, an initiation step and a secondary step, were determined for the process of the reactions of $\mathrm{ClF}_{3} \mathrm{O}$ and $n$ decane. A roaming mechanism was proposed for the initiation step. According to the IRC calculations, a HF molecule was formed at the beginning of the reaction, and then the $\mathrm{H}-\mathrm{F}$ bond broke after rotating around to give $\mathrm{ClFO}$, fluorinated decane and another new HF molecule. The initiation reactions were barrier-less and extremely exothermic. The average released energy of P1, P2 and P3 was $412.9 \mathrm{~kJ} \mathrm{~mol}^{-1}$. The radical mechanism was shown to be less likely by the excited state computation. The reactions of $\mathrm{ClFO}$ and $n$-decane and the thermal decomposition of $n$-decane were secondary reactions and competed with each other. ClFO was less reactive then $\mathrm{ClF}_{3} \mathrm{O}$. It needed to absorb $116.3 \mathrm{~kJ} \mathrm{~mol}^{-1}$ to react with $n$ - 
decane. The occurrence of thermal decomposition of $n$-decane was confirmed by the emission spectra and gaseous product distribution. The emission spectra of $\mathrm{CH}$ and $\mathrm{C}_{2}$ radical intermediates were observed. Hydrogen, ethylene and acetylene were the main gaseous products.

\section{Conflicts of interest}

There are no conflicts to declare.

\section{Acknowledgements}

This project was funded by the Special Projects of Taishan Scholar Construction Work (Grant No. ts20120518) and the China University of Petroleum (Beijing) Scientific Research Fund (Grant No. 2462015YQ0601). The authors thank Dr Yang $\mathrm{Hu}$ at the North China Institute of Science \& Technology for the help with obtaining emission spectra.

\section{References}

1 A. Guber and U. Köhler, J. Mol. Struct., 1995, 348, 209.

2 Y. Saito, Sens. Mater., 2002, 14, 231.

3 C. J. Gugliemini and A. D. Johnson, Semicond. Int., 1999, 22, 1.

4 A. Pierce, M. Taylor, J. Sauer and D. Ruppert, Solid State Technol., 1997, 40, 107.

5 D. Pilipovich, C. B. Lindahl, C. J. Schack, R. D. Wilson and K. O. Christe, Inorg. Chem., 1972, 11, 2189.

6 D. Pilipovich, H. H. Rogers and R. D. Wilson, Inorg. Chem., 1972, 11, 2192.

7 K. O. Christe and E. C. Curtis, Inorg. Chem., 1972, 11, 2196.

8 C. J. Schack, C. B. Lindahl, D. Pilipovich and K. O. Christe, Inorg. Chem., 1972, 11, 2201.

9 K. O. Christe, C. J. Schack and D. Pilipovich, Inorg. Chem., 1972, 11, 2205.

10 K. O. Christe and E. C. Curtis, Inorg. Chem., 1972, 11, 2209.

11 K. O. Christe, E. C. Curtis and C. J. Schack, Inorg. Chem., 1972, 11, 2212.

12 H. Oberhammer and K. O. Christe, Inorg. Chem., 1982, 21, 273.

13 K. R. Brower, J. Fluorine Chem., 1986, 31, 333.

14 L. Niu, Z. Liu, S. Wang, Y. Luo and X. Sun, Acta Chim. Sin., 2010, 68, 1787.
15 H. Du, G. Wang, X. Gong and H. Xiao, Int. J. Quantum Chem., 2012, 112, 1291.

16 C. B. Baddiel and C. F. Cullis, Symp. Combust., 1961, 8, 1089.

17 H. Yan, Y. F. Luo, H. Q. Gao, P. Yan and K. S. Luo, Chin. J. Energ. Mater., 2015, 23, 346.

18 C. Gonzalez and H. B. Schlegel, J. Chem. Phys., 1989, 90, 2154.

19 C. Gonzalez and H. B. Schlegel, J. Phys. Chem., 1990, 94, 5523.

20 M. J. Frisch, G. W. Trucks, H. B. Schlegel, G. E. Scuseria, M. A. Robb, J. R. Cheeseman, J. A. Montgomery, T. Vreven, K. N. Kudin, J. C. Burant, J. M. Millam, S. S. Iyengar, J. Tomasi, V. Barone, B. Mennucci, M. Cossi, G. Scalmani, N. Rega, G. A. Petersson, H. Nakatsuji, M. Hada, M. Ehara, K. Toyota, R. Fukuda, J. Hasegawa, M. Ishida, T. Nakajima, Y. Honda, O. Kitao, H. Nakai, M. Klene, X. Li, J. E. Knox, H. P. Hratchian, J. B. Cross, V. Bakken, C. Adamo, J. Jaramillo, R. Gomperts, R. E. Stratmann, O. Yazyev, A. J. Austin, R. Cammi, C. Pomelli, J. W. Ochterski, P. Y. Ayala, K. Morokuma, G. A. Voth, P. Salvador, J. J. Dannenberg, V. G. Zakrzewski, S. Dapprich, A. D. Daniels, M. C. Strain, O. Farkas, D. K. Malick, A. D. Rabuck, K. Raghavachari, J. B. Foresman, J. V. Ortiz, Q. Cui, A. G. Baboul, S. Clifford, J. Cioslowski, B. B. Stefanov, G. Liu, A. Liashenko, P. Piskorz, I. Komaromi, R. L. Martin, D. J. Fox, T. Keith, A. Laham, C. Y. Peng, A. Nanayakkara, M. Challacombe, P. M. W. Gill, B. Johnson, W. Chen, M. W. Wong, C. Gonzalez and J. A. Pople, Gaussian 03, Revision C.02.

21 C. Zhang, P. Li, J. Guo and X. Li, Energy Fuels, 2012, 26, 1107. 22 C. Zhang, H. Tang, C. Zhang, Y. Zhao, P. Li and X. Li, Chem. Phys. Lett., 2013, 556, 13.

23 J. Shi, Y. Ma, S. Li, J. Wu, Y. Zhu and J. Teng, Energy Fuels, 2017, 31, 4808.

24 J. Shi, Y. Ma, S. Li and L. Zhang, Energy Fuels, 2017, 31, 10535.

25 G. S. Hammond, J. Am. Chem. Soc., 1955, 77, 334.

26 Y. Xiao, J. M. Longo, G. B. Hieshima and R. J. Hill, Ind. Eng. Chem. Res., 1997, 36, 4033.

27 R. Bleekrode and W. C. Nieuwpoort, J. Chem. Phys., 1965, 43, 3680 . 